\section{Plaque Stabilization by Proprotein Convertase Subtilisin/Kexin Type 9 Inhibitor in a Patient With Familial Hypercholesterolemia Undergoing Percutaneous Coronary Intervention}

Hideki Kitahara, MD, PhD; Naoto Mori, MD;

Yuichi Saito, MD, PhD;

Takashi Nakayama, MD, PhD;

Yoshihide Fujimoto, MD, PhD;

Yoshio Kobayashi, MD, PhD

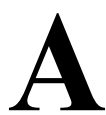

78-year-old man with familial hypercholesterolemia underwent percutaneous coronary intervention for a left anterior descending artery stenosis. Given that low-density lipoprotein cholesterol (LDL-C) was $>110 \mathrm{mg} / \mathrm{dL}$ even under strong statin therapy, a proprotein convertase subtilisin/kexin type 9 (PCSK9) inhibitor (evolocumab; $140 \mathrm{mg}$ every 2 weeks) was used, and LDL-C was maintained at $<30 \mathrm{mg} / \mathrm{dL}$. At baseline and at 12 -month follow-up, a non-culprit lesion in the left circumflex artery was observed on intravascular ultrasound (IVUS), which was seen to have unchanged lumen volume (from 7.3 to $7.4 \mathrm{~mm}^{3} / \mathrm{mm}$ ), and slightly reduced vessel and plaque volumes (from 14.8 to $14.1 \mathrm{~mm}^{3} / \mathrm{mm}$; from 7.5 to $6.7 \mathrm{~mm}^{3} / \mathrm{mm}$, respectively). Lipid component on integrated backscatterIVUS was decreased (from $55.8 \%$ to $47.6 \%$ ), while other components were increased (calcification: from $1.5 \%$ to $2.9 \%$; dense fibrosis: from $5.2 \%$ to $7.4 \%$; fibrosis: from $37.5 \%$ to $42.1 \%$; Figure).

PCSK9 inhibitors can drastically reduce LDL-C, and lead to atherosclerotic plaque regression. ${ }^{1}$ As observed in the present case, PCSK9 inhibitors may induce plaque stabilization as well as plaque regression, which possibly contributes to the reduction of cardiovascular events. ${ }^{2}$

Received August 27, 2018; accepted September 4, 2018; J-STAGE Advance Publication released online October 2, 2018 Time for primary review: 8 days

Department of Cardiovascular Medicine, Chiba University Graduate School of Medicine, Chiba, Japan

Mailing address: Hideki Kitahara, MD, PhD, Department of Cardiovascular Medicine, Chiba University Graduate School of Medicine, 1-8-1 Inohana, Chuo-ku, Chiba 260-8677, Japan. E-mail: hkitahara@chiba-u.jp

ISSN-1346-9843 All rights are reserved to the Japanese Circulation Society. For permissions, please e-mail: cj@j-circ.or.jp

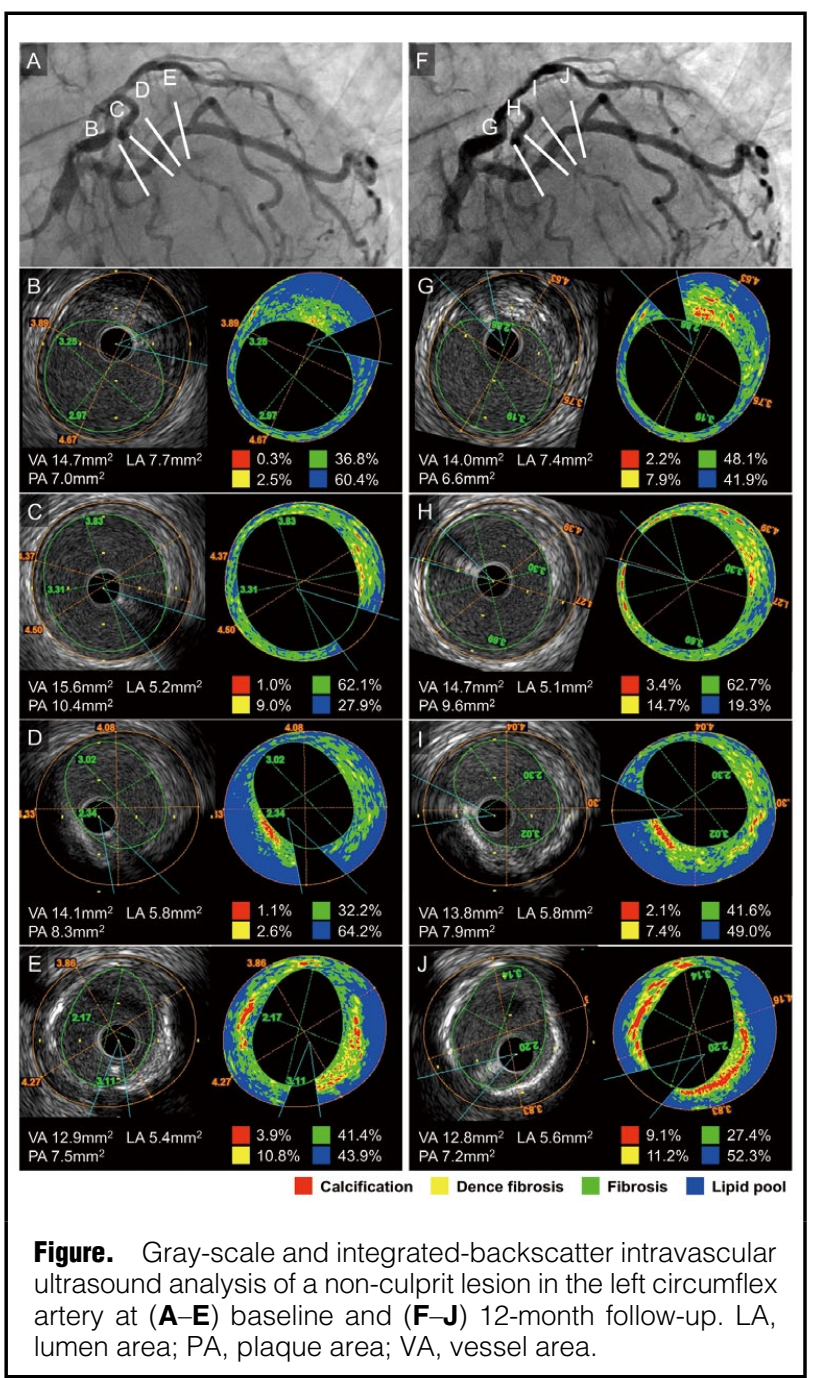

\section{Disclosures}

The authors declare no conflicts of interest.

\section{References}

1. Nicholls SJ, Puri R, Anderson T, Ballantyne CM, Cho L, Kastelein JJ, et al. Effect of evolocumab on progression of coronary disease in statin-treated patients: The GLAGOV randomized clinical trial. JAMA 2016; 316: 2373-2384.

2. Sabatine MS, Giugliano RP, Keech AC, Honarpour N, Wiviott $\mathrm{SD}$, Murphy SA, et al. Evolocumab and clinical outcomes in patients with cardiovascular disease. N Engl J Med 2017; 376: $1713-1722$ 